\title{
MOVIMENTOS SOCIAIS NA ATUALIDADE: ALGUMAS REFLEXÕES
}

\section{SOCIAL MOVEMENTS IN THE PRESENT TIME: SOME REFLECTIONS}

\author{
Regina Maura Rezende ${ }^{1}$
}

\begin{abstract}
RESUMO: O presente estudo tem por objetivo trazer a luz reflexões acerca do processo vivenciado pelos movimentos sociais, sobretudo nas ultimas duas décadas. Sabe-se que os movimentos sociais se constituíram em elementos de grande relevância na história das conquistas sociais no Brasil. Nascendo da iniciativa popular, cujo objetivo tem origem e é motivado pelas mazelas ocasionadas pela divergência entre o universo do capital em detrimento do trabalho, e, assim, do trabalhador, os movimentos sociais se constituem em elementos de resistência e posicionamento político da sociedade. Na medida em que a sociedade é subsumida pelo fluxo do capital, os novos modelos de produção, com vistas ao empreendimento da exacerbação da mais valia, os movimentos sociais somaram-se as reivindicações amplas e coletivas. Hoje se tem como exemplo os movimentos de defesa à natureza, à etnias, à orientação sexual, os movimentos pela terra e pelo teto, os quais se configuram em manifestos de ordem particular. Trazer a luz a temática dos movimentos sociais e seus fluxos e refluxos na sociedade brasileira é o objetivo do presente estudo. Longe de oportunizar conceitos definitivos, o presente estudo vem trazer reflexões acerca da temática, e, na mesma medida, possibilidades de intervenção do profissional da área das ciências sociais aplicadas e, de forma mais íntima, tecer aproximações acerca das possibilidades de atuação do serviço social, inserido no contexto do debate pela edificação do direito e cidadania.
\end{abstract}

Palavras-chave: Movimentos Sociais. Sociedade. Sujeito Político.

ABSTRACT : This study aims to bring the light reflections on the process experienced by social movements, especially in the last two decades. It is known that social movements were formed on matters of great importance in the history of social gains in Brazil. Born of popular initiative, whose goal originates from and is motivated by the ills caused by the divergence between the universe of capital over labor, and thus the worker, the social movements become elements of resistance and political position in society. To the extent that society is subsumed by the flow of capital, new forms of production, aiming at the development of exacerbation of surplus value, social movements were added to the broad claims and collective. Today we have the example of defense motions to the nature, ethnicity, sexual orientation, movements by land and ceiling, which have become manifest in a particular order. Bring to light the theme of social movements and its ebbs and flows in Brazilian society is the objective of this study. Far from creating opportunity definitive concepts, this study brings reflections on the subject, and to the same extent, possibilities of professional intervention in the area of applied social sciences and, more intimately, to make approximations about the possibilities of performance of social service, Within the context of the debate for the edification of law and citizenship

KEYWORDS: Social Movements. Society. Political Subject

1 * Doutora e Mestre em Serviço Social. Docente da Universidade Federal do Triangulo Mineiro - UFTM Especialista em Política Social e Serviço Social pela Universidade de Brasília - UNB. Membro do Grupo de Estudos sobre Saúde, Qualidade de Vida e Relações de Trabalho QUAVISSS. 


\section{MOVIMENTOS SOCIAIS NA ATUALIDADE}

"Movimentos sociais são fenômenos históricos, decorrentes de lutas sociais. Colocam atores específicos sob as luzes da ribalta em períodos determinados. Com as mudanças estruturais e conjunturais da sociedade civil e política, eles se transformam" ( Gohn, 2007, p.19-20).

No Brasil, nos últimos períodos, sobretudo nas ultimas duas décadas os movimentos sociais sofreram radicais mudanças/transformações que, segundo Gohn (2007), mudanças advindas do período conhecido como "década noliberal". Dentre essas transformações pode-se identificar o papel de destaque da Ongs como direção dos movimentos sociais; houve um predomínio das Ongs como direção política dos espaços de organização.

Segundo Gonh ainda, os movimentos sociais populares perderam sua força mobilizadora, pois as políticas integradoras exigiram a interlocução com organizações institucionalizadas. As Ongs ganharam poder e projeção, sobretudo, pelas parcerias edificadas com o poder público.

Para melhor entendimento acerca dessa temática, faz-se necessária uma breve contextualização acerca dos movimentos sociais. De inicio cabe destacar que conforme a autora ainda, a ausência na literatura de obras baseadas na análise dos movimentos sociais brasileiro e latino americano fez com que houvesse uma inadequação do uso de teorias elaboradas no exterior, principalmente inspirados pelo silencio sobre o paradigma norte-americano.

Segundo Gohn, (2007) "não há teoria, concepção e tipo únicos de movimento social" e, "Há várias teorias formadas em paradigmas teóricos explicativos" (p.327).

Pode-se definir movimento social como "fenômenos históricos decorrentes de lutas sociais e se transformam", segundo Gohn (2007, p.20), embora essa definição caiba uma série de outra análises, tendo em vista que, pela sua mobilidade e flexibilidade no entendimento social tenda a ter um caráter de transitoriedade. Os movimentos sociais transitam, fluem, acontecem em espaços não consolidados das estruturas e organizações sociais (p.12). Conforme destacado, não há um conveito, mas vários conceitos que podem efetuar aproximações acerca de sua definição e, para Habermas "são inovadores e atuam como "lentes"”. 
Os movimentos sociais são definidos como fluidos, fragmentados, perpassados por outros projetos sociais, "como uma aranha eles tecem redes que se quebram facilmente, dada sua fragilidade" (p.343)

No Brasil e na América Latina, os movimentos sociais nos anos de 1970 são inspirados nos dilemas da doutrina marxista, identificados pela contradição e luta de classes. Pós anos de 1980, o chamado novo movimento social apresenta-se com identidade e, na busca pela legitimação de sua autonomia. Pós anos 1990 verifica-se uma refração dos mesmos, havendo flagrante decréscimo da militância. Conforme Gohn (2007, p. 339) ainda, os movimentos sociais passaram a ser ritmados por reivindicações mais globais, como por exemplo, os movimentos antiglobalização, em defesa do meio ambiente e como o Fórum Social Mundial. Na mesma medida estes passam a ter uma militância mais seletiva e qualitativa que segundo a autora ainda, passam a ter mais racionalidade e estratégia e menos ação, mais formas de menos esperança de transformação.

Os movimentos sociais se qualificam por serem movimentos de segmentos excluídos, usualmente pertencentes à camadas populares; se constituem em movimentos de luta por melhores condições de vida e de trabalho, no meio urbano ou rural, destacando-se aqui o exemplo dos Movimentos do Sem Teto e Movimento do Sem Terra; e, são movimentos globais ou globalizantes como o exemplo do Fórum Social Mundial.

Segundo Gohn (2007), ainda,

“... Nunca haverá uma teoria completamente pronta e acabada sobre eles (movimentos sociais). Trata-se de uma característica do próprio objeto de estudos. Os movimentos são fluidos, fragmentados, perpassados por outros processos sociais. Como uma teia de aranha eles tecem redes que se quebram facilmente, dada sua fragilidade.... Mas, sempre presentes" (p.343).

No novo século, novos personagens entram em cena quando se promove a discussão acerca dos movimentos sociais: se achegam a estes, interesses de classes específicas, como o movimento em defesa das etnias, como o caso do movimento negro e seu emblemático debate acerca das cotas nas universidades, os movimentos gays com interesse especifico na defesa da legalização da união homo afetiva, dentre outros.

Nessa nova configuração, o tema dos movimentos sociais deixa de ser objeto de pesquisa apenas do mundo acadêmico e passa a constituir objeto de 
interesse das Ongs e outra entidades do terceiro setor, assim como do universo público. Todos como a mesma perspectiva: é necessário entender para intervir nessa "nova" realidade social. Um exemplo disso é a constituição do "Observatório Social da América Latina”, o qual traz importantes considerações acerca dos movimentos sociais na América Latina, como a importante descrição do vinculo histórico entre os movimentos sociais e os partidos políticos. Entende-se, nesse sentido que, a identidade política dos movimentos sociais não é único, mas podendo variar em contextos e conjunturas diferentes.

Nessa temática uma importante preocupação é a tendência contemporânea do olhar direcionado ao sujeito social, ou seja, multifacetada, onde os princípios individuais se sobrepõe ao coletivo, dando uma conotação pseudocoesão, e, nessa perspectiva o sujeito social passa a ser analisado numa intimidade que faz com que se perca a força coletiva. Trata-se de ter uma visão multifacetada em relação ao sujeito social, e, sozinhos esses múltiplos sujeitos perdem sua força coletiva e ainda, o ponto de convergência para a ser o próprio Estado; tem-se como medida a execução de tarefas programadas (analisadas, avaliadas e monitoras pelo próprio Estado!)

Os sentidos de justiça social, igualdade, cidadania, emancipação e direitos passam a dar lugar a outras categorias como capital social, inclusão social, reconhecimento social, empoderamento da comunidade, auto-estima, responsabilidade social, sustentabilidade, entre outros.

Nesse contexto do "novo" mundo do trabalho, observa-se a diminuição de emprego na economia formal e o crescimento das atividades informais, do processo de terceirização da produção, do "semi-trabalho e do não trabalho". Mais que o reiterado processo de mais valia absoluta descrito por Marx ao abordar o movimento do capital na sociedade do trabalho, tem-se de forma ainda mias ampliada o exercito de reserva, agora travestido sob a forma da grande massa de desempregados e, não raro, também agonizante das políticas públicas, subalternos de políticas sociais fragmentadas, cujo pai Estado, relega seus filhos ao abandono.

Nessa perspectiva, esse mesmo Estado sai as ruas e à mídia televisiva, sobretudo, conclamando à sociedade a se "engajar" nos movimentos solidários, nas Ongs (espaço ocupado por instituições situadas entre o Estado e o mercado) e, a se responsabilizar por segmentos carentes de políticas sociais inclusivas, cuja tônica, não raro, tem como meta a promoção da inclusão de segmentos populacionais, 
excluídos do pertencimento ao processo de edificação da cidadania. Ora, tomar para si a responsabilidade de cuidar dos frutos da mazela do capital, assumindo a assim, a responsabilidade de guarnecer a população não grata pelo mundo do capital e pelo mercado: esse passa a ser o discurso emblemático assumido pela "burguesia" . Estudos apontam que a maioria das ações edificadas para "resgate da cidadania" instituídas pelas Ongs contam com a significativa colaboração da classe média, e, da classe que vive do trabalho.

Segundo Neto (2003) o capital monopolista impera na medida em que se refaz e credita ao Estado e a sociedade civil a resolução de suas mazelas, ou seja, os frutos das desigualdades edificadas pelo capital monopolista são "acudidos" pelo Estado e, pela sociedade civil, através de ações quase sempre paliativas: o capital opera a orquestra da desigualdade, mas, isenta-se da cena principal e, quando presente é mero expectador no aguardo das honrarias advindas às suas benesses, obviamente demarcadas elas isenções fiscais.

Nesse cenário as Ongs figuram como instrumentos de mediação entre coletivos organizados e o sistema de poder governamental e também entre os grupos privados e instituições não governamentais, cujo objetivo maior é a oferta de serviços, cujo "esforço" estatal e do capital não conseguiram edificar o alcance e resolutividade necessários. Via de regra, fortalecem-se políticas de apoio a Economia Solidária, que segundo Gon fortalece o local via políticas públicas locais de geração de renda e empreendimentos de economia solidárias nos seus mais diversos tipos e segmentos.

Os anos pós 1990 foram marcados por uma "nova" forma do Estado se relacionar com a sociedade civil organizada. Trata-se de um momento de reorganização do Estado enquanto "centro operacional" do bem estar social. Aquele Estado protetor, o Welfare State, perece de fôlego e cai de joelhos os ditames neoliberalistas que, em pedunia, opera a orquestra que dará o tom ao social que agoniza pela distancia, ineficiência e, não raro, ausência deste Estado.

Os movimentos sociais nesse contexto perdem espaço de ação e autenticidade no âmbito de suas reivindicações. Há uma evidente refração de sua função enquanto elemento questionador e reivindicador no contexto social. Contudo, há que se considerar que, conforme Gohn (p.20), "enquanto a sociedade não 
resolver seus problemas básicos de desigualdade sociais, opressão e inclusão, haverá lutas, haverá movimentos... e haverá teorias para explicá-los".

\section{REFERENCIAS BIBLIOGRÁFICAS}

ANTUNES, Ricardo. Adeus ao trabalho? ensaio sobre as metamorfoses e a centralidade do mundo do trabalho. 6. ed. São Paulo: Cortez, 1999.

Os sentidos do trabalho: ensaio sobre a firmação e a negação do trabalho. São Paulo: Boitempo, 2005.

BEHRING, Elaine Rossetti. Acumulação Capitalista, fundo público e política social. In: BOSCHETTI, Ivanete. Política Social no capitalismo: tendências contemporâneas. São Paulo: Cortez, 2008, p. 44 -63.

GOHN, Maria da Glória. O Protagonismo da Sociedade Civil: movimentos sociais, Ongs e Redes Solidárias. São Paulo: Cortez, 2002.

IAMAMOTO, Marilda Vilela. A Questão Social no Capitalismo. Temporalis - Revista da Associação Brasileira de Ensino e Pesquisa em Serviço Social. ABEPSS, v. 2, n. 3, p. 9-32, jan./jun. 2001a.

Serviço Social em Tempo de Capital Fetiche: capital financeiro, trabalho e questão social. São Paulo: Cortez, 2008.

; CARVALHO, Raul de. Relações sociais e Serviço Social no Brasil: esboço de uma interpretação histórico- metodológica. 7. ed. São Paulo: Cortez, 1990.

NETTO, José Paulo. Cinco notas a propósito da Questão Social. Temporalis Revista da Associação Brasileira de Ensino e Pesquisa em Serviço Social. ABEPSS, v. 2, n. 3, p. 41-49, jan./jun. 2001.

.FHC e a Política Social: um desastre para as massas trabalhadoras. In: LESBAUPIN, Ivo (Org.). O desmonte da nação: balanço do Governo FHC. 3. ed. Petrópolis, RJ: Vozes, 1999. p. 75- 89.

OLIVEIRA, Francisco de. Crítica à razão dualista: o ornitorrinco. São Paulo: Boitempo, 2003.

PEREIRA, Potyara Amazoneida Pereira. Mudanças estruturais, política social e papel da família: crítica ao pluralismo de bem-estar. In: SALES, Mione Apolinário; 
MATOS, Maurílio de Castro; LEAL, Maria Cristina (Org.). Política Social, família e juventude: uma questão de direitos. São Paulo: Cortez, 2004. p. 25-42.

Cidadania e (in)justiça social: embates teóricos e possibilidades atuais. In: FREIRE, Lúcia Maria de Barros; FREIRE, Sirlene de Moraes; CASTRO, Alba Tereza Barroso. Serviço Social, política social e trabalho: desafios e perspectivas para o século XXI. São Paulo: Cortez, 2006. p. 98-116.

Questão Social, Serviço Social e Direitos de Cidadania. Temporalis, Brasília, ano 2, n. 3, jan-jul 2001, p. 51-61.

SANTANA, Luis Gustavo. Responsabilidade Social. Centro Luterano Univesitário de Palmas. 2008 (mimeo)

SANTOS. Wanderley Guilherme. Cidadania e justiça: a política social na ordem brasileira. Rio de Janeiro: Campus, 1987.

SPOSATI, Aldaíza. Regulação Social tardia: características sociais latinoamericanas na pasagem entre o segundo e o terceiro milênio. In: VII Congresso Internacional del CLAD sobre la Reforma del Estado Y de la Administración Pública, Lisbona, Portugal, 8 -11 Oct. 2002, mimeo.

VIEIRA, Evaldo. O Estado e a sociedade civil perante o ECA e a LOAS. Serviço Social \& Sociedade. São Paulo: Cortez, no. 56, mar 1998, p. 9 -22. 